\title{
RESPONSABILIDADE DAS PESSOAS JURÍDICAS EM INFRAÇÕES AMBIENTAIS EM FACE DO PRINCÍPIO DO NE BIS IN IDEM: UMA ABORDAGEM POLÍTICO- CRIMINAL
}

\author{
Daiane Ayumi Kassada* \\ Érika Mendes de Carvalho**
}

Resumo: O presente estudo analisa o princípio ne bis in idem no ordenamento jurídico brasileiro como recurso político-criminal à contenção do punitivismo estatal. Nessa perspectiva, questiona a sobreposição de sanção administrativa e penal no âmbito dos ilícitos ambientais praticados por pessoas jurídicas e situa o princípio ne bis in idem como estratégia de contenção de iniciativas criminalizadoras, que apenas reforçam o caráter simbólico da intervenção penal e contribuem para a articulação de uma política criminal orientada à expansão do poder punitivo, em detrimento de princípios garantistas elementares.

Palavras-chave: Política Criminal; Princípio ne bis in idem; Responsabilidade penal das pessoas jurídicas; Limitações ao poder sancionador; Ilícitos ambientais.

\section{RESPONSIBILITY OF LEGAL PERSONS IN ENVIRONMENTAL INFRINGEMENTS IN THE LIGHT OF THE "NE BIS IN IDEM" PRINCIPLE: A POLITICAL-CRIMINAL APPROACH}

\begin{abstract}
The present study analyzes the "ne bis in idem" principle in the Brazilian legal system as a political-criminal resource to contain the state punitivism. In this perspective, it questions the overlapping of administrative and penal sanctions in the scope of environmental illicit practices done by legal entities and places the "ne bis in idem" principle as a strategy to contain criminal initiatives that only reinforce the symbolic character of criminal intervention and contribute to the articulation of a criminal policy oriented to the expansion of punitive power, to the detriment of elementary guarantee principles.
\end{abstract}

Keywords: Criminal Policy; Principle ne bis in idem; Criminal liability of legal persons; Limitations on sanctioning power; Environmental infringements.

\footnotetext{
${ }^{*}$ Especialista em Ciências Penais pela Universidade Estadual de Maringá (UEM). Mestranda em Direito Penal, Medicina Forense e Criminologia pela Universidade de São Paulo (USP). Endereço postal: Largo São Francisco, 95 - São Paulo-SP, CEP 01005-010. E-mail: daianekassada@usp.br.

${ }^{* *}$ Doutora e Pós-Doutora em Direito Penal pela Universidad de Zaragoza (Espanha). Professora Associada de Direito Penal na Universidade Estadual de Maringá (UEM). Bolsista PNPD/CAPES na UENP. Endereço postal: Avenida Colombo, 5790, Campus Universitário, Zona 07 - Maringá, PR, CEP 87020-900. E-mail: erika.mendes0510@hotmail.com.
} 


\section{INTRODUÇÃO}

O exame do princípio do ne bis in idem tem suscitado discussões calorosas no âmbito jurídico em diversos países, em especial a Espanha, cujo Tribunal Constitucional registra toda uma evolução e densidade jurisprudencial acerca do tema. ${ }^{1}$

Aliás, não é só nos países europeus em que o ne bis in idem vêm despertando profundos debates, mas os Tribunais Constitucionais da América Latina, a exemplo do Peru ${ }^{2}$ e do Chile ${ }^{3}$ também apresentam decisões instigantes.

Contudo, tal intensidade de debate não se verifica até o presente momento nos Tribunais Superiores brasileiros, motivo pelo qual, apesar da publicação recente de escritos importantes realizados no Brasil ${ }^{4}$, é fundamental retomar a análise do ne bis in idem no ordenamento jurídico brasileiro, notadamente no que se refere à admissibilidade ou não da sobreposição concomitante de sanção administrativa e penal no âmbito dos ilícitos ambientais praticados por pessoas jurídicas.

O marco normativo fundamental para a realização dessa análise reside no artigo 225, $\S 3^{\circ}$ da Constituição Federal de 1988, o qual dispõe que "as condutas e atividades consideradas lesivas ao meio ambiente sujeitarão os infratores, pessoas físicas ou jurídicas, a sanções penais e administrativas, independentemente da obrigação de reparar os danos causados", bem como na Lei n. 9.605/98 e no Decreto 6.514/08, que prevêem inúmeras infrações - penais e administrativas, respectivamente - bem como um dispositivo específico - o art. $3^{\circ}$ da referida Lei 9.605/98 - que expressamente determina a responsabilidade civil, administrativa e penal da pessoa jurídica, assegurando que "as pessoas jurídicas serão responsabilizadas administrativa,

\footnotetext{
1 "De fato, tanto a doutrina espanhola como a jurisprudência ordinária e constitucional se dedicaram, especialmente nas últimas três décadas, a examinar o conteúdo, fundamento e alcance do princípio em apreço, considerado um dos fundamentos do direito penal moderno. A ausência de um reconhecimento constitucional expresso não impediu que o Tribunal Constitucional espanhol dedicasse particular atenção à elaboração do princípio non bis in idem, impulsionado pelas doutrinas administrativa e penal.” (Cf. CARVALHO, Érika Mendes de; CARDOSO, Sônia Letícia de Méllo; SANTIAGO, Nestor Eduardo Araruna. Duplicidade de sanções ambientais e o princípio non bis in idem. In: Pensar: Revista de Ciências Jurídicas, vol. 18, n. 2, p. 431-469. Fortaleza: Universidade de Fortaleza, mai/ago 2013. p. 435).

${ }^{2}$ Uma análise interessante sobre a evolução da jurisprudência do Tribunal Constitucional do Peru, cf. CARO CORIA, Dino Carlos. El principio de "ne bis in idem" en la jurisprudencia del Tribunal Constitucional. Revista Brasileira de Ciências Criminais, São Paulo, v. 15, n. 66, p. 9-52, mai./jun. 2007.

${ }^{3}$ MAÑALICH R., Juan Pablo. El principio ne bis in idem en el derecho penal chileno. Revista peruana de ciencias penales, Lima, n. 26, p. 351-386, 2013.

${ }^{4}$ Cf. COSTA, Helena Regina Lobo da. Direito Penal Econômico e Direito Administrativo Sancionador: ne bis in idem como medida de política sancionadora integrada. Tese de Livre Docência. Faculdade de Direito da Universidade de São Paulo. São Paulo. 2013; SABOYA, Keity. Ne bis in Idem: História, Teoria e Perspectivas. Rio de Janeiro: Lumen Juris, 2014.
}

Rev. de Criminologias e Políticas Criminais | e-ISSN: 2526-0065 | Maranhão | v. 3 | n. 2 | p. 49 - 67 | Jul/Dez. 2017 


\section{RESPONSABILIDADE DAS PESSOAS JURÍDICAS EM INFRAÇÕES AMBIENTAIS EM FACE DO PRINCÍPIO DO NE BIS IN IDEM: UMA ABORDAGEM POLÍTICO-CRIMINAL}

civil e penalmente conforme o disposto nesta Lei (9.605/98), nos casos em que a infração seja cometida por decisão de seu representante legal ou contratual, ou de seu órgão colegiado, no interesse ou benefício da sua entidade".

Nesse sentido, embora a responsabilidade penal da pessoa jurídica ainda seja polêmica acerca da sua admissibilidade ou não em decorrência de toda principiologia e garantias que regem a atuação do Direito Penal ${ }^{5}$, o fato é que o ordenamento jurídico brasileiro prevê - tanto em nível constitucional como em nível infraconstitucional - a referida responsabilização em matéria ambiental, sem prejuízo da responsabilidade administrativa pelo mesmo fato em determinados casos.

Não há muitas dificuldades em reconhecer o princípio do ne bis in idem dentro de um mesmo ramo do Direito, isto é, é plenamente aceitável que ninguém possa ser sancionado e processado penalmente mais de uma vez pelo mesmo fato tido como crime ou que ninguém poderá ser sancionado ou processado administrativamente pelo mesmo fato considerado como infração administrativa.

Apesar de diversos os pontos polêmicos e as questões complexas referentes ao princípio do ne bis in idem ${ }^{6}$, o cerne da discussão reside na viabilidade deste incidir sobre todo o ordenamento jurídico: isto é, consiste precisamente em examinar possibilidade ou não de o mesmo sujeito receber uma dupla sanção ou ser processado pelo mesmo fato com igual fundamento pelas diversas esferas de poder sancionador do Estado.

Nessa perspectiva, Jacobo López Barja de Quiroga assevera que "no âmbito misto administrativo-jurisdicional penal, a problemática se apresenta quando a Administração e a

\footnotetext{
${ }^{5}$ Cf., na doutrina nacional, entre outros, COSTA, Helena Regina Lobo da. Proteção Penal Ambiental: viabilidade, efetividade e tutela por outros ramos do Direito. São Paulo: Saraiva, 2010. p. 108/ SHECAIRA, Sérgio Salomão. Responsabilidade penal da pessoa jurídica. 2. ed. São Paulo: Método, 2003/ DOTTI, René Ariel; PRADO, Luiz Regis (Coords.). Responsabilidade penal da pessoa jurídica: em defesa do princípio da imputação subjetiva. 4.ed. São Paulo: RT, 2013.p. 129-162; BUSATO, Paulo César, GUARAGNI, Fábio André. Responsabilidade penal da pessoa jurídica. Curitiba: Juruá, 2012.

${ }^{6}$ HENDLER, Edmundo S. Una regla que confirma sus excepciones: ne bis in idem. In: HENDLER, Edmundo S. Las garantías penales y procesales: enfoque histórico-comparado. Buenos Aires: Del Puerto, 2004. p. 148. BARJA DE QUIROGA, Jacobo López. El principio: non bis in idem. Madrid: Dykinson, 2004. p. 13. Nesse sentido, Daniel R. PASTOR afirma que "muito mais difícil e complexo é resolver, na verdade, o que já se vê o que resta do debate, a saber, quais são os alcances precisos da proibição [do ne bis in idem]. Por isso resulta rentável examinar a partir de agora uma determinada tendência atual sobre a extensão do ne bis in idem, dado que certas aplicações deste princípio tomaram um rumo inesperado e é preciso colocá-las no banco de prova dos fundamentos da proibição". (Cf. PASTOR, Daniel R. Nuevas tareas para el principio ne bis in idem?. In: ANITUA, Gabriel Ignacio; TEDESCO, Ignacio F. La cultura penal: homenaje al profesor Edmundo S. Hendler. Buenos Aires: Del Puerto, 2009. p. 499).
}

Rev. de Criminologias e Políticas Criminais | e-ISSN: 2526-0065 | Maranhão | v. 3 | n. 2 | p. 49 - 67 | Jul/Dez. 2017 
Jurisdição penal impõem, ou estão em vias de fazê-lo, cada uma dentro do seu alcance, uma sanção quanto ao mesmo fato e à mesma pessoa".7

Outrossim, a possibilidade de imposição múltipla de sanções, embora de caráter distinto (penal e administrativa) àquele (pessoa física ou jurídica) que pratica uma determinada infração ambiental que se enquadra (em tese) tanto como uma infração administrativa quanto como uma infração penal, desafia a verificação da violação do conteúdo do princípio do ne bis in idem.

O presente estudo, com lastro em método de caráter hipotético-dedutivo, pretende delimitar, do ponto de vista teórico, o princípio do ne bis in idem e examinar algumas hipóteses que visam a situá-lo como uma estratégia político-criminal importante a fim de reduzir as respostas punitivas de caráter penal, especialmente em face da criminalidade ambiental.

\section{NE BIS IN IDEM: DELIMITAÇÃO CONCEITUAL}

É de conhecimento geral que o princípio do ne bis in idem possui um aspecto material ${ }^{8}$ e um aspecto processual. ${ }^{9}$ Quanto ao primeiro, o ne bis in idem assegura que ninguém poderá ser sancionado duas vezes pelo mesmo fato e pelo mesmo fundamento. Já com relação ao

\footnotetext{
${ }^{7}$ BARJA DE QUIROGA, Jacobo López. El principio: non bis in idem. Madrid: Dykinson, 2004. p. 38. Segundo Luis-Román PUERTA o princípio do ne bis in idem é um princípio geral do Direito e possui aplicabilidade em todos os ramos jurídicos que desenvolvem um poder sancionador (cf. PUERTA, Luis-Román. Duplicidad sancionadora, administrativa y penal, non bis in idem. In: MARTÍN PALLÍN, José Antonio (Dir.). Extranjeros y derecho penal. Madrid: Consejo General del Poder Judicial, 2004. p. 380). Ramón García Albero faz referência à STC 154/1990 do Tribunal Constitucional da Espanha para ressaltar a incompatibilidade de sanções penais e administrativas pelo mesmo fato em procedimentos distintos correspondente a ordens jurídicas sancionadoras distintas (cf. GARCÍA ALBERO, Ramón. Non bis in idem: material y concurso de leyes penales. 1. ed. Barcelona: CEDECS, 1995. p. 61). Ainda sobre o tema, cf. GARCÍA ALBERO, Ramón. La relación entre ilícito penal e ilícito administrativo: texto y contexto de las teorías sobre la distinción de ilícitos. In: QUINTERO OLIVARES, Gonzalo; MORALES PRATS, Fermín (Coord.). El nuevo derecho penal español: estudios penales en memoria del profesor José Manuel Valle Muñiz. Pamplona: Aranzadi, 2001. p. 295-400.

${ }^{8}$ GARCÍAS PLANAS, Gabriel. Consecuencias del principio non bin in idem en derecho penal. Anuario de derecho penal y ciencias penales, Madrid, v. 42, n. 1, p. 109-123., jan./abr. 1989. p. 110. Com relação ao ne bis in idem na vertente material, este "implica a vedação da sanção múltipla pelo mesmo, e a juízo da doutrina majoritária vige quando concorre a chamada tripla identidade: do sujeito, fato e fundamento" (Cf. CARO CORIA, Dino Carlos. El principio de "ne bis in idem" en la jurisprudencia del Tribunal Constitucional. Revista Brasileira de Ciências Criminais, São Paulo, v. 15, n. 66, p. 9-52., mai./jun. 2007. p. 12). Cf. também MAÑALICH R., Juan Pablo. El principio ne bis in idem en el derecho penal chileno. Revista peruana de ciencias penales, Lima, n. 26, p. 351-386., 2013. p. 353-354. "O ne bis in idem substancial proíbe uma segunda sanção que resulta excessiva como resposta ao ilícito culpável do autor". (Cf. OTTAVIANO, Santiago. Sanción penal, sanción administrativa y ne bis in idem. In: YACOBUCCI, Guillermo Jorge; LAPORTA, Mario H.; RAMÍREZ, Nicolás D. Derecho penal empresario. Montevidéu: B. de F., 2010. p. 748).

${ }^{9}$ SABOYA, Keity. Ne bis in idem: história, teoria e perspectivas. Rio de Janeiro: Lumen Juris, 2014. p. 23-24.
}

Rev. de Criminologias e Políticas Criminais | e-ISSN: 2526-0065 | Maranhão | v. 3 | n. 2 | p. 49 - 67 | Jul/Dez. 2017 


\section{RESPONSABILIDADE DAS PESSOAS JURÍDICAS EM INFRAÇÕES AMBIENTAIS EM FACE DO PRINCÍPIO DO NE BIS IN IDEM: UMA ABORDAGEM POLÍTICO-CRIMINAL}

segundo, tem-se a "exclusão da possibilidade de um julgamento sobre o fato ante a existência de outro julgamento (anterior ou simultâneo) relativo ao mesmo fato."10

Ainda assim, interessante registrar, neste estudo, a dimensão transversal do ne bis in idem apresentada por Keity Saboya, uma vez que "as repercussões das dimensões tradicionais do princípio do ne bis in idem continuam incipientes e mais ainda quando relacionadas à proibição de acumulação de sanções penais e sanções administrativas pelos mesmos fatos e fundamentos. ${ }^{11}$ Nesse sentido, o princípio do ne bis in idem pode ser analisado sob um âmbito misto (diversos ramos do Direito e, no presente caso, administrativo e penal/judicial) ${ }^{12}$.

Contudo, desde já, algumas ressalvas são de suma importância no que concerne às implicações oriundas do conteúdo contido no princípio do ne bis in idem. A primeira é que o princípio veda a dupla aplicação concreta de sanções pelo mesmo fato com base no mesmo fundamento em face da mesma pessoa - seja ela física ou jurídica -, mas não impede que um mesmo fato seja duplamente valorado pelo legislador e que este, por questão de razoabilidade e motivação, possa entender pela dupla necessidade de tutela (administrativa e penal) do mesmo bem jurídico (no caso, o ambiente) em face de uma determinada prática infracional, desde que seja por fundamentos distintos. Aqui, insta mencionar, conforme bem ressaltado por Helena Regina Lobo da Costa, a jurisprudência da Corte Constitucional da Bélgica no sentido de reconhecer inexistência à inobservância do princípio do ne bis in idem "caso o legislador preveja os ilícitos penais e administrativos para os mesmos fatos em tese". ${ }^{13}$

Em síntese, o ne bis in idem não obsta que um mesmo fato seja tipificado como infração concomitantemente na ordem jurídica penal e administrativa. ${ }^{14}$ Assim, na verdade, "uma das questões que se levanta acerca da existência de uma dupla ordem sancionadora (a

\footnotetext{
${ }^{10}$ MAÑALICH R., Juan Pablo. El principio ne bis in idem en el derecho penal chileno. Revista peruana de ciencias penales, Lima, n. 26, p. 351-386., 2013. p. 352. Ainda quanto à definição da proibição do ne bis in idem, cf. OTTAVIANO, Santiago. Sanción penal, sanción administrativa y ne bis in idem. In: YACOBUCCI, Guillermo Jorge; LAPORTA, Mario H.; RAMÍREZ, Nicolás D. Derecho penal empresario. Montevidéu: B. de F., 2010. p. 745.

${ }^{11}$ SABOYA, Keity. Ne bis in Idem: História, Teoria e Perspectivas. Rio de Janeiro: Lumen Juris, 2014. p. 259.

${ }^{12}$ BARJA DE QUIROGA, Jacobo López. El principio: non bis in idem. Madrid: Dykinson, 2004. p. 36. Neste contexto, Ramon García Albero destaca uma relevante decisão do Tribunal Constitucional da Espanha STC de 03 de outubro de 1983, na qual este concluiu pela impossibilidade de duplicidade de sanções administrativas e penais pelo mesmo fato. (cf. GARCÍA ALBERO, Ramón. Non bis in idem: material y concurso de leyes penales. 1. ed. Barcelona: CEDECS, 1995. p. 57).

${ }^{13}$ COSTA, Helena Regina Lobo da. Direito Penal Econômico e Direito Administrativo Sancionador: ne bis in idem como medida de política sancionadora integrada. Tese de Livre Docência. Faculdade de Direito da Universidade de São Paulo. São Paulo. 2013. p. 205.

${ }^{14}$ PUERTA, Luis-Román. Duplicidad sancionadora, administrativa y penal, non bis in idem. In: MARTíN PALLÍN, José Antonio (Dir.). Extranjeros y derecho penal. Madrid: Consejo General del Poder Judicial, 2004. p. 39.
}

Rev. de Criminologias e Políticas Criminais | e-ISSN: 2526-0065 | Maranhão | v. 3 | n. 2 | p. 49 - 67 | Jul/Dez. 2017 
penal e a do direito administrativo sancionador) é a de determinar os critérios distintivos das mesmas e fixar seus respectivos limites". ${ }^{15}$

A matéria ambiental adquire grande relevância para examinar a densidade normativa do princípio do ne bis in idem, uma vez que "é precisamente nesse domínio que se verifica uma expressiva concorrência de normativas sancionadoras."16

Essa delimitação de critérios deve ir além dos genuinamente formais, ultrapassando a ideia de que a resposta jurídica no âmbito administrativo se dá por uma autoridade administrativa através da imposição de uma penalidade e que, no âmbito penal, a imposição de uma resposta jurídica se concretiza pela autoridade judicial através da imposição de uma pena ${ }^{17}$. Deve-se repensar o dogma clássico da independência das instâncias sancionadoras administrativa e penal, pois mantê-lo de forma rígida pode ser, na verdade, uma postura em dissonância com a Constituição Federal de $1988 .{ }^{18}$

Quanto à matéria ambiental no ordenamento jurídico brasileiro no que diz respeito à responsabilidade da pessoa (natural/jurídica), é de se indagar acerca da existência ou não de identidade de sujeitos, fatos e fundamentos na sanção administrativa e na sanção penal prevista para um determinado tipo penal contra o meio ambiente e se entre eles é possível aferir um espaço que permite indevidamente a mitigação ou mesmo a violação do princípio do ne bis in idem no seu aspecto material. ${ }^{19}$

Isto porque, para a incidência do princípio do ne bis in idem, exige-se uma identidade tríplice: a) sujeito ${ }^{20}$; b) fato; c) fundamento. ${ }^{21}$ É necessário que esta identidade tríplice esteja

15 PUERTA, Luis-Román. Duplicidad sancionadora, administrativa y penal, non bis in idem. In: MARTÍN PALLÍN, José Antonio (Dir.). Extranjeros y derecho penal. Madrid: Consejo General del Poder Judicial, 2004. p. 39.

${ }^{16}$ CARVALHO, Érika Mendes de; CARDOSO, Sônia Letícia de Méllo; SANTIAGO, Nestor Eduardo Araruna. Duplicidade de sanções ambientais e o princípio non bis in idem. In: Pensar: Revista de Ciências Jurídicas, vol. 18, n. 2, p. 431-469. Fortaleza: Universidade de Fortaleza, mai/ago 2013. p. 432.

${ }^{17}$ PUERTA, Luis-Román, op. cit., p. 39.

18 Segundo Renato de Mello Jorge Silveira, "parece ser esse o caso brasileiro, no qual, sob o argumento da independência de instâncias, ao arrepio da Constituição e sem a devida consideração da mais relevante experiência jurídica comparada, se admite a dupla punição pelo mesmo fato, nas instâncias penal e administrativa. (Cf. SILVEIRA, Renato de Mello Jorge; GOMES JUNIOR, João Florêncio de Salles. Direito penal, direito administrativo sancionador e a questão do ne bis in idem: o parâmetro da jurisprudência internacional. In: BLAZECK, Luiz Mauricio Souza; MARZAGÃO JR., Laerte I.; ALCKMIN, Geraldo. Direito administrativo sancionador. São Paulo: Quartier Latin, 2014. p. 290).

${ }^{19}$ CORCOY BIDASOLO, Mirentxu; GALLEGO SOLER, José Ignacio. Infracción administrativa e infracción penal en el ámbito del delito medioambiental: ne bis in idem material y procesal : comentario a la STC 177/199, de 11 de octubre. Actualidad Penal, Madrid, v. 1, n. 8, p. 159-178., fev. 2000. p. 163.

${ }^{20}$ Com relação ao sujeito, a doutrina majoritária exige que não haja relação de sujeição especial com a Administração Pública para que possa falar em identidade de sujeito e, por consequência, possibilitar a aplicação do princípio do ne bis in idem. (Cf. BARJA DE QUIROGA, Jacobo López. El principio: non bis in idem. Madrid: Dykinson, 2004. p. 35-36).

${ }^{21}$ BARJA DE QUIROGA, Jacobo López. El principio: non bis in idem. Madrid: Dykinson, 2004. p. 35. 


\section{RESPONSABILIDADE DAS PESSOAS JURÍDICAS EM INFRAÇÕES AMBIENTAIS EM FACE DO PRINCÍPIO DO NE BIS IN IDEM: UMA ABORDAGEM POLÍTICO-CRIMINAL}

presente cumulativamente para que seja possível a incidência concreta do referido princípio. Assim, se a incidência dupla de sanções penal e administrativa consistir em níveis distintos de tutela conferida a um determinado bem jurídico não há que se falar em vulneração do ne bis in idem.

Com relação ao sujeito, exige-se "tão somente que não recaia sobre o mesmo sujeito passivo mais de uma consequência de natureza punitiva em face dos mesmos fatos e do mesmo fundamento". ${ }^{22}$ A doutrina majoritária entende que não há que se falar em identidade de sujeito entre "pessoa jurídica e uma pessoa natural quando entre ambas existe uma relação de gestão ou representação, e a sanção obedece ao mesmo fato e fundamento" ${ }^{23}$, pois nestes casos formalmente se estaria diante de pessoas diferentes, tal como acontece no ordenamento jurídico brasileiro quanto à matéria ambiental.

Porém, neste contexto, é relevante destacar que "de modo excepcional a STC espanhol 177/1999 de 11 de outubro apreciou uma vulneração ao ne bis in idem pela condenação ao representante legal de uma empresa por delito ambiental (privação de liberdade e multa) e a sanção administrativa contra dita empresa por infração à Lei de Águas (multa de mesma quantia)." 24

No que tange à tutela do meio ambiente por parte do poder sancionador do Estado, seja na esfera administrativa, seja na esfera penal, cabe advertir que quando "se opera com critérios quase formais [conforme apontados anteriormente], que identificam infração administrativa e penal, se corre o risco de que o Direito Penal ambiental assuma uma indevida função promocional, simbólica se preferível, incidindo de fato quase exclusivamente em casos de bagatela". 25

\footnotetext{
${ }^{22}$ SABOYA, Keity. Ne bis in Idem: História, Teoria e Perspectivas. Rio de Janeiro: Lumen Juris, 2014. p. 169.

${ }^{23}$ CARO CORIA, Dino Carlos. El principio de "ne bis in idem" en la jurisprudencia del Tribunal Constitucional. Revista Brasileira de Ciências Criminais, São Paulo, v. 15, n. 66, p. 9-52, mai./jun. 2007. p. 14-15.

${ }^{24}$ Ibid., p. 15. Para uma análise precisa e minuciosa sobre a STC espanhol 177/1999. Vide também CORCOY BIDASOLO, Mirentxu; GALLEGO SOLER, José Ignacio. Infracción administrativa e infracción penal en el ámbito del delito medioambiental: ne bis in idem material y procesal: comentario a la STC 177/199, de 11 de octubre. Actualidad Penal, Madrid, v. 1, n. 8, p. 159-178., fev. 2000; cf. también VICENTE MARTÍNEZ, Rosario de. Teoría y práctica o el dr. Jekyll y Mr. Hyde: a propósito de la sentencia del Tribunal Constitucional 177/1999, de 11 de octubre, sobre el principio ne bis in idem. Actualidad Penal, Madrid, v. 2, n. 22, p. 473-486., jun. 2000. Cf. também VICENTE MARTÍNEZ, Rosario de. Teoría y práctica o el dr. Jekyll y Mr. Hyde: a propósito de la sentencia del Tribunal Constitucional 177/1999, de 11 de octubre, sobre el principio ne bis in idem. Actualidad Penal, Madrid, v. 2, n. 22, p. 473-486., jun. 2000.

${ }^{25}$ CORCOY BIDASOLO, Mirentxu; GALLEGO SOLER, José Ignacio. Infracción administrativa e infracción penal en el ámbito del delito medioambiental: ne bis in idem material y procesal: comentario a la STC 177/199, de 11 de octubre. Actualidad Penal, Madrid, v. 1, n. 8, p. 159-178., fev. 2000. p. 167-168.
}

Rev. de Criminologias e Políticas Criminais | e-ISSN: 2526-0065 | Maranhão | v. 3 | n. 2 | p. 49 - 67 | Jul/Dez. 2017 
$\mathrm{Na}$ verdade, o que o ne bis in idem veda é a duplicidade de sanções administrativa e penal no caso em que há identidade de sujeito, fato e fundamento, pois a permissão desta dupla sanção revelaria indevida desproporcionalidade quanto à culpabilidade do agente e à magnitude do injusto no caso concreto.

Portanto, infere-se que o requisito do ne bis in idem que mais suscita divergências para verificar a observância do referido princípio reside no fundamento que embasa a aplicação de duas sanções - administrativa e penal - sobre o mesmo fato em face da mesma pessoa. ${ }^{26}$

Para examinar a identidade ou não de fundamento, é necessário compreender qual o alcance de uma sanção aplicada pelo poder sancionador estatal. Sempre que houver razões distintas de sancionar o mesmo fato em diferentes esferas, é possível a incidência de uma dupla sanção - isto é, uma administrativa e outra penal - em virtude da prática de um mesmo ilícito ambiental. Todavia, caso se constate a identidade de fundamento - além do sujeito e dos fatos - estar-se-á diante de um bis in idem, que deve ser resolvido com lastro nos princípios do conflito aparente de normas.

Assim, segundo Ramón García Albero, "se efetivamente se trata de um conflito é porque somente cabe aplicar a sanção da norma que melhor apreende a ilicitude do fato, é óbvio que para essa concreta infração o Ordenamento pretendeu apenas uma sanção, embora aparentemente - haja uma pluralidade de cominações. Pois bem, na delimitação entre o efetivo concurso de normas sancionadoras e o mero conflito, parece que a proporcionalidade por si só não pode exercer papel algum, mas que tal tarefa deve ser realizada com critérios lógicos e teleológicos que desvelem o solapamento desvalorativo de ambos os preceitos". ${ }^{27}$

\footnotetext{
${ }^{26}$ OTTAVIANO, Santiago. Sanción penal, sanción administrativa y ne bis in idem. In: YACOBUCCI, Guillermo Jorge; LAPORTA, Mario H.; RAMÍREZ, Nicolás D. Derecho penal empresario. Montevidéu: B. de F., 2010. p. 741.

${ }^{27}$ GARCÍA ALBERO, Ramón. Non bis in idem: material y concurso de leyes penales. Barcelona: CEDECS, 1995. p. 88-89. Nesse mesmo sentido, Dino Carlos Caro Coria assegura que "nesta perspectiva de suposição de unidade de lei, como sucede no concurso aparente, não será possível a sanção múltipla dado que o desvalor do fato é abarcado pela sua totalidade por uma só norma. Distinto é o caso do concurso real ou ideal de infrações, nos casos em que o desvalor do resultado não é abarcado plenamente por uma só norma, mas por vários, sendo válido impor mais de uma sanção". (Cf. CARO CORIA, Dino Carlos. El principio de "ne bis in idem" en la jurisprudencia del Tribunal Constitucional. Revista Brasileira de Ciências Criminais, São Paulo, v. 15, n. 66, p. 9-52, mai./jun. 2007. p. 16-17). Ainda assim, "é crucial reparar aqui que a proibição [ne bis in idem] não se vê violada, pelo mesmo, se o reconhecimento de um autêntico concurso de delitos se expressa adequadamente e de conformidade com a representação legislativa, a magnitude do desvalor corresponde ao objeto da respectiva sentença condenatória (Cf. MAÑALICH R., Juan Pablo. El principio ne bis in idem en el derecho penal chileno. Revista peruana de ciencias penales, Lima, n. 26, p. 351-386., 2013. p. 355).
}

Rev. de Criminologias e Políticas Criminais | e-ISSN: 2526-0065 | Maranhão | v. 3 | n. 2 | p. 49 - 67 | Jul/Dez. 2017 


\section{RESPONSABILIDADE DAS PESSOAS JURÍDICAS EM INFRAÇÕES AMBIENTAIS EM FACE DO PRINCÍPIO DO NE BIS IN IDEM: UMA ABORDAGEM POLÍTICO-CRIMINAL}

Em resumo, "deve dotar-se ao ne bis in idem material de conteúdo normativo, a proibição de sancionar mais de uma vez deve operar sempre que se trate do mesmo conteúdo de injusto ou de ilícito, da mesma infração, sem se importar se dito conteúdo está refletido em uma norma penal ou administrativa". 28

Outra observação de grande relevância é que o ne bis in idem é axiologicamente neutro, isto é, não é possível extrair, a partir do conteúdo em si do referido princípio, qual a natureza da sanção - penal ou administrativa - que deve prevalecer ou ceder diante do caso concreto em face da mesma pessoa com base nos mesmos fatos e fundamentos. ${ }^{29}$

Desta forma, o que o princípio ne bis in idem veda é a sanção plural e, por isso, Ramón García Albero dispõe que "somente o princípio [ne bis in idem] não determina qual das normas aparentemente concorrentes - no âmbito dos respectivos ordenamentos - haverá de prevalecer em detrimento das restantes para que o non bis in idem seja respeitado. Isso supõe, definitivamente, desvincular o conteúdo desta manifestação do princípio da regra de subordinação do poder sancionador administrativo do Direito Penal." 30

\section{O PRINCÍPIO DO NE BIS IN IDEM NO ORDENAMENTO JURÍDICO BRASILEIRO}

A partir destas anotações iniciais, é perceptível qual o âmbito de aplicação e o limite de incidência do ne bis in idem. Ainda assim, para que seja possível analisar o ne bis in idem no ordenamento jurídico brasileiro, é necessário averiguar se em alguma parte deste se assegura o referido princípio e se sua densidade normativa incide em todos os ramos do referido ordenamento e entre todos os âmbitos jurídicos, em especial o penal e o administrativo.

\footnotetext{
${ }^{28}$ CARO CORIA, Dino Carlos. El principio de "ne bis in idem" en la jurisprudencia del Tribunal Constitucional. Revista Brasileira de Ciências Criminais, São Paulo, v. 15, n. 66, p. 9-52, mai./jun. 2007. p. 16. Ainda assim, "a diferença entre a infração administrativa e penal no âmbito ambiental obedece não somente questões estruturais na configuração típica, mas que, essencialmente, se fundamenta em considerações teleológicas, na medida em que o âmbito próprio do injusto penal persegue dintintas finalidades que o do ilícito administrativo. Assim, embora o injusto penal deve perseguir proteção de bens jurídicos-penais concretos em situações concretas, conforme aos parâmetros de lesividade enunciados, para a existência de um ilícito administrativo, por sua vez, basta seguir critérios de afetação geral - regulatórios - ou estadísticos, barra que descreva situações de perigo estandardizadas". (Cf. CORCOY BIDASOLO, Mirentxu; GALLEGO SOLER, José Ignacio. Infracción administrativa e infracción penal en el ámbito del delito medioambiental: ne bis in idem material y procesal: comentario a la STC 177/199, de 11 de octubre. Actualidad Penal, Madrid, v. 1, n. 8, p. 159-178., fev. 2000. p. 168).

${ }^{29}$ GARCÍA ALBERO, Ramón. Non bis in idem: material y concurso de leyes penales. Barcelona: CEDECS, 1995. p. 85.

${ }^{30}$ Ibid., p. 85.
}

Rev. de Criminologias e Políticas Criminais | e-ISSN: 2526-0065 | Maranhão | v. 3 | n. 2 | p. 49 - 67 | Jul/Dez. 2017 
Insta registrar que, ao contrário da Lei Fundamental da Alemanha (art. 103, parágrafo $\left.3^{\circ}\right)^{31}$ e da Espanha ${ }^{32}$, a Constituição Federal brasileira de 1988 não possui nenhum dispositivo que expressamente prevê, a proibição do princípio do ne bis in idem. Ao contrário, em matéria ambiental, no seu artigo $225, \S 3^{\circ}$, há a possibilidade de responsabilidade administrativa e penal da pessoa jurídica quanto à prática de atos considerados lesivos ao meio ambiente.

Porém, com fundamento no art. $5^{\circ}, \S 2^{\circ}$ da Constituição Federal de $1988^{33}$, o qual dispõe que "os direitos e garantias expressos nesta Constituição não excluem outros decorrentes do regime e dos princípios por ela adotados, ou dos tratados internacionais em que a República Federativa do Brasil seja parte", é possível verificar que o ne bis in idem foi adotado - ao menos - de forma implícita quando o Brasil aderiu à Convenção Americana sobre Direitos Humanos (Pacto San José da Costa Rica) através do Decreto n. 678/92 no qual o artigo 8.4 garante que “o acusado absolvido por sentença passada em julgado não poderá ser submetido a novo processo pelos mesmos fatos" ${ }^{34}$, evidenciando-se claramente a vedação do ne bis in idem no seu aspecto processual.

Embora o aspecto processual do ne bis in idem tenha uma estreita relação com sua vertente material - uma vez que ao impedir que a mesma pessoa se sujeite a dois processos em relação ao mesmo fato obsta também, por consequência, a incidência de uma segunda sanção -

\footnotetext{
${ }^{31}$ MAÑALICH R., Juan Pablo. El principio ne bis in idem en el derecho penal chileno. Revista peruana de ciencias penales, Lima, n. 26, p. 351-386, 2013. p. 352. Porém, tal como o Brasil, há outras Constituições que também não possuem previsão expressa do princípio do ne bis in idem em seu bojo normativo constitucional, a exemplo da Espanha e do Chile. Cf. MAÑALICH R., Juan Pablo. El principio ne bis in idem en el derecho penal chileno. Revista peruana de ciencias penales, Lima, n. 26, p. 351-386., 2013. p. 353.

32 GARCÍAS PLANAS, Gabriel. Consecuencias del principio non bin in idem en derecho penal. Anuario de derecho penal y ciencias penales, Madrid, v. 42, n. 1, p. 109-123., jan./abr. 1989. p.112. Aqui insta salientar que, embora a Constituição da Espanha não contemple expressamente o princípio do ne bis in idem com caráter geral, "o artigo 45.3 da Constituição Espanhola reconhece parcialmente o princípio do ne bis in idem no terreno da proteção ambiental, pois assinala que "se estabelecerão sanções penais ou, se for o caso, administrativas. E ainda que dita Constituição não consagre o princípio com caráter geral, uma ampla jurisprudência do Tribunal Constitucional da Espanha o deduz do princípio da legalidade previsto no artigo 25.1 da Constituição Espanhola". (Cf. CARO CORIA, Dino Carlos. El principio de "ne bis in idem" en la jurisprudencia del Tribunal Constitucional. Revista Brasileira de Ciências Criminais, São Paulo, v. 15, n. 66, p. 9-52, mai./jun. 2007. p. 11).

PUERTA, Luis-Román. Duplicidad sancionadora, administrativa y penal, non bis in idem. In: MARTÍN PALLÍN, José Antonio (Dir.). Extranjeros y derecho penal. Madrid: Consejo General del Poder Judicial, 2004. p. 44.

${ }^{33}$ Segundo Flávia Piovesan, "por força do art. $5^{\circ}$, $\S 2^{\circ}$ e $2^{\circ}$, a Carta de 1988 atribui aos direitos enunciados em tratados internacionais hierarquia de norma constitucional, incluindo-os no elenco dos direitos constitucionalmente garantidos, que apresentam aplicabilidade imediata. Os demais tratados internacionais têm força hierárquica infraconstitucional, nos termos do art. 102, III, $b$, do texto (que admite o cabimento de recurso extraordinário de decisão que declarar a inconstitucionalidade de tratado), e se submetem à sistemática de incorporação legislativa". (Cf. PIOVESAN, Flavia. O valor jurídico dos tratados e seu impacto na ordem internacional. In: PIOVESAN, Flavia. Temas de direitos humanos. 9. ed. São Paulo: Saraiva, 2016. p. 163-175. p. 170.

${ }^{34}$ D’URSO, Luiz Flávio Borges. Menos Direito Penal e Mais Direito Administrativo Sancionador. In: BLAZECK, Luiz Mauricio Souza; MARZAGÃO JR., Laerte I.; ALCKMIN, Geraldo. Direito administrativo sancionador. São Paulo: Quartier Latin, 2014. p. 207.
}

Rev. de Criminologias e Políticas Criminais | e-ISSN: 2526-0065 | Maranhão | v. 3 | n. 2 | p. 49 - 67 | Jul/Dez. 2017 


\section{RESPONSABILIDADE DAS PESSOAS JURÍDICAS EM INFRAÇÕES AMBIENTAIS EM FACE DO PRINCÍPIO DO NE BIS IN IDEM: UMA ABORDAGEM POLÍTICO-CRIMINAL}

traz consigo um conteúdo autônomo. Com efeito, no caso, por exemplo, de um sujeito ser absolvido $^{35}$ em uma das esferas sancionadoras do Estado (e, portanto, mesmo sem a imposição de sanção), este estará impedido de iniciar um novo processo em face dos mesmos fatos sob igual fundamento em desfavor da pessoa, seja ela física ou jurídica.

Em razão disso, há quem entenda que o artigo 8.4 do Pacto San José da Costa Rica, quando se refere expressamente à vertente processual do princípio do ne bis in idem, indiretamente também vedaria o seu aspecto material. ${ }^{36}$

Ademais, é possível depreender a vigência do princípio do ne bis in idem no Brasil também através do Pacto Internacional sobre Direitos Civis e Políticos que foi ratificado através do Decreto n. 592/92, no qual o artigo 14.7 do referido instrumento legislativo dispõe que "ninguém poderá ser processado ou punido por um delito pelo qual já foi absolvido ou condenado por sentença passada em julgado, em conformidade com a lei e os procedimentos penais de cada país". ${ }^{37}$ Assim, o referido Pacto Internacional consagra tanto o aspecto material quanto o processual do princípio do ne bis in idem. ${ }^{38}$

É curioso notar que atualmente a responsabilidade penal da pessoa jurídica está sendo relativamente pouco debatida se comparada com tempos anteriores, ao passo que, o direito administrativo sancionador tem conquistado espaço como forma de responsabilizar a pessoa jurídica pelas infrações por ela cometidas, inclusive as ambientais.

Essa constatação se torna interessante porque, apesar de ainda não se ter construído uma dogmática penal sólida e com princípios e categorias específicos, hábil a lidar de forma coerente e efetiva com a natureza peculiar da pessoa jurídica quanto à sua responsabilização penal, parte da doutrina aponta claramente que a responsabilidade penal da pessoa jurídica se

\footnotetext{
${ }^{35}$ Keity Saboya afirma que "o entendimento aqui proposto é que não se deve permitir a renovação do ius puniendi estatal depois de ter sido resolvido o caso penal por meio de sentença ou decisão definitiva transitada em julgado". (Cf. SABOYA, Keity. Ne bis in Idem: História, Teoria e Perspectivas. Rio de Janeiro: Lumen Juris, 2014. p. 176). Dino Carlos Caro Coria assegura que "se a jurisdição penal conclui que os fatos são inexistentes ou não estão provados, nenhum outro órgão público, jurisdicional ou administrativo, pode pretender acreditar o contrário mediante outra investigação e deve ter por inocente o cidadão em face aos fatos imputados." (Cf. CARO CORIA, Dino Carlos. El principio de "ne bis in idem" en la jurisprudencia del Tribunal Constitucional. Revista Brasileira de Ciências Criminais, São Paulo, v. 15, n. 66, p. 9-52, mai./jun. 2007. p. 37-38).

${ }^{36}$ D`URSO, Luiz Flávio Borges. Menos Direito Penal e Mais Direito Administrativo Sancionador. In: BLAZECK, Luiz Mauricio Souza; MARZAGÃO JR., Laerte I.; ALCKMIN, Geraldo. Direito administrativo sancionador. São Paulo: Quartier Latin, 2014. p. 207.

${ }^{37}$ SABOYA, Keity. Ne bis in idem: história, teoria e perspectivas. Rio de Janeiro: Lumen Juris, 2014. p. 35. Cf. também CARVALHO, Érika Mendes de; CARDOSO, Sônia Letícia de Méllo; SANTIAGO, Nestor Eduardo Araruna. Duplicidade de sanções ambientais e o princípio non bis in idem. In: Pensar: Revista de Ciências Jurídicas, vol. 18, n. 2, p. 431- 469. Fortaleza: Universidade de Fortaleza, mai/ago 2013. p. 456.

${ }^{38}$ MAÑALICH R., Juan Pablo. El principio ne bis in idem en el derecho penal chileno. Revista peruana de ciencias penales, Lima, n. 26, p. 351-386., 2013. p. 353.
}

Rev. de Criminologias e Políticas Criminais | e-ISSN: 2526-0065 | Maranhão | v. 3 | n. 2 | p. 49 - 67 | Jul/Dez. 2017 
dá por razões de política criminal ${ }^{39}$, já que a expressão simbólica ${ }^{40}$ da aplicação da pena estaria ausente nas sanções administrativas impostas pelo poder sancionador administrativo estatal.

Contudo, a partir do momento em que se começa a constatar que, em determinadas situações, a sanção de caráter administrativa pode igualmente assumir um caráter simbólico ${ }^{41}$ (embora com intensidade distinta daquele próprio da sanção penal) e que o Direito Administrativo sancionador pode sim intervir também para sancionar condutas graves - e não apenas condutas de baixa gravidade -, seria interessante analisar a relação que pode existir entre o poder administrativo sancionador e o poder punitivo penal.

Tomando como ponto de partida uma equivalência entre as instâncias sancionadoras (penal e administrativa) e constatando suas forças simbólicas, seria fundamental verificar, primeiramente, o espaço para atuação do princípio ne bis in idem como forma de contenção de uma delas (e, por consequência, como freio à expansão do poder sancionador estatal como um todo) sempre que se constatar que a pessoa (física ou jurídica) poderá sofrer mais de uma sanção ou estará submetida a mais de um processo em face dos mesmos fatos com base nos mesmos fundamentos.

\section{CONCLUSÃO}

Ainda que a responsabilidade penal da pessoa jurídica em matéria ambiental seja formalmente amparada constitucional e infraconstitucionalmente, conforme anteriormente salientado, a sua aplicação concreta em face de atos que violam dispositivos que configuram

\footnotetext{
${ }^{39}$ A título de exemplo, corretamente, Renato de Mello Jorge Silveira afirma que “(...) talvez a maior justificativa à sua implantação [responsabilidade penal da pessoa jurídica] seja de caráter político-criminal. A partir da compreensão de que nas sociedades pós-industriais, sociedades de risco que são, grande parte das condutas criminosas econômicas e ambientais são praticadas por pessoas jurídicas, por uma questão de coerência sistêmica, torna-se necessário um certo grau de reprovação penal destas. No entanto, essa construção se encontra dentro de um espectro penal, o qual, já visto, é cercado de dúvidas quanto à sua eficácia no campo dos interesses difusos. (Cf. SILVEIRA, Renato de Mello Jorge. Direito penal supra-individual: interesses difusos. São Paulo: Revista dos Tribunais, 2003. p. 198).

${ }^{40}$ Sobre apontamentos críticos acerca do caráter simbólico do Direito Penal, cf. COSTA, Helena Regina Lobo da. Proteção Penal Ambiental: viabilidade, efetividade e tutela por outros ramos do Direito. São Paulo: Saraiva, 2010. p. 109-152. SILVEIRA, Renato de Mello Jorge. Direito penal supra-individual: interesses difusos. São Paulo: Revista dos Tribunais, 2003. p.168-173. HASSEMER, Winfried. Derecho penal simbólico y protección de bienes jurídicos. Trad. Elena Larrauri. Nuevo Foro Penal 51/22, 1991.

41 "Por sua vez, o direito administrativo sancionador vem adquirindo evidente caráter estigmatizador". (Cf. COSTA, Helena Regina Lobo da. Direito Penal Econômico e Direito Administrativo Sancionador: ne bis in idem como medida de política sancionadora integrada. Tese de Livre Docência. Faculdade de Direito da Universidade de São Paulo. São Paulo. 2013. p. 160).
} 


\section{RESPONSABILIDADE DAS PESSOAS JURÍDICAS EM INFRAÇÕES AMBIENTAIS EM FACE DO PRINCÍPIO DO NE BIS IN IDEM: UMA ABORDAGEM POLÍTICO-CRIMINAL}

ilícitos ambientais - embora com previsão normativa para tanto -, de início já apresenta flagrante violação ao princípio da legalidade, pois os tipos penais não apresentam preceito secundário (isto é, previsão das margens penais) orientado especificamente às pessoas jurídicas. Infere-se apenas a existência de dispositivos com uma previsão geral de quais seriam as penas aplicadas às pessoas jurídicas (arts. 21 a 23, Lei 9.605/98) seja que delito for, ficando a cargo do magistrado selecionar de forma casuística a espécie de sanção correspondente, delimitar seu quantum específico a depender do delito e da gravidade da sua prática quando da dosimetria da pena e, inclusive, cumular distintas espécies de sanções para o mesmo autor.

Quando se defende a possibilidade da responsabilidade penal da pessoa jurídica cumulada com a responsabilidade administrativa - sempre que não houver diferença quanto ao fundamento da dupla punição/persecução penal - simplesmente para reforçar o caráter simbólico da primeira ante a suposta insuficiência do poder administrativo sancionador do Estado, há um inequívoco reforço da expansão punitiva e da expressão simbólica da punição penal. É uma opção político-criminal claramente oposta a um minimalismo punitivo e que chancela, ainda que indiretamente, o bis in idem.

E se há indicação da suposta insuficiência ou ineficiência do poder sancionador administrativo do Estado, o desafio é constatar se realmente existe esta ineficiência invocada diante do caso concreto ou se esse discurso apenas se dirige a reforçar o caráter simbólico da resposta penal, mesmo quando esta, na prática, viola princípios penais de garantia e se mostra altamente seletiva no tocante à punição de pessoas (físicas e jurídicas).

Com efeito, ainda que se constatem deficiências concretas na atuação do Direito Administrativo sancionador, é necessário indagar também: qual seria a função que o Direito Penal poderia desempenhar diante do suposto fracasso do Direito Administrativo sancionador? Quais as expectativas depositadas na resposta punitiva penal? O que significaria uma intervenção do poder punitivo ou sancionador bem-sucedida?

Outrossim, considerando que as sanções administrativas, em determinados casos, também podem ter efeito simbólico, ainda que em menor medida, a reflexão reside em: o que Direito Penal pode oferecer, de fato, para suprir a insuficiência ou ineficiência do poder administrativo sancionador em face da mesma pessoa sobre o mesmo fato e iguais fundamentos?

Tal questionamento adquire relevância porque, quando se examina a lei penal ambiental brasileira (Lei n. 9.605/98) constata-se que inúmeros tipos penais são reproduzidos como meras infrações administrativas ambientais no Decreto 6.514/08. Em realidade, a opção

Rev. de Criminologias e Políticas Criminais | e-ISSN: 2526-0065 | Maranhão | v. 3 | n. 2 | p. 49 - 67 | Jul/Dez. 2017 
político-criminal sempre foi pelo Direito Penal, o que contraria o discurso acadêmico de intervenção mínima. A intervenção punitiva em matéria ambiental, especificamente após a Constituição Federal de 1988, foi primeiramente projetada em termos penais e, apenas dez anos depois, chancelada em termos administrativos (Decreto 6.514/08). Houve, na realidade, uma repetição dos ilícitos penais como ilícitos administrativos, o que revela que uma seleção das condutas mais graves pelo Direito Penal nunca aconteceu. Há o claro protagonismo do Direito Penal em matéria ambiental, acompanhado pela criminalização de pessoas jurídicas como forma de (supostamente) conter condutas lesivas (ou abstratamente perigosas) ao ambiente.

Para fins de ilustração, verifica-se que o artigo 35 da Lei n. 9.605/98 tipifica como crime determinadas formas de pesca, tal hipótese é transladada na íntegra no artigo 36 do Decreto 6.514/08 que trata igual conduta também como infração administrativa. Imagina-se, então, uma determinada empresa que trabalha com a industrialização de peixes enlatados, por exemplo, e que tem um setor especializado em realização de pesca através de meio proibido pela autoridade competente para fomentar os lucros do referido negócio. Em razão disso, a referida pessoa jurídica é sancionada administrativamente com multa e suspensão total das atividades. Considerando que a sanção mais gravosa aplicável à pessoa jurídica é a suspensão total das atividades - que nada mais significa que o fim da existência da própria pessoa jurídica - constata-se, na verdade, que foi exaurida a intensidade máxima de sanção possível e disponível ao Estado para se valer de seu poder sancionador.

Assim, se a sanção de suspensão total das atividades pode ser aplicada tanto pelo direito administrativo sancionador (art. $3^{\circ}$, IX do Decreto 6.514/08) quanto pelo poder punitivo penal do Estado (art. 22, I c/c $\S 1^{\circ}$, Lei $\mathrm{n}^{\circ}$. 9.605/98), tem-se que o ne bis in idem poderia atuar - uma vez aplicada a sanção correspondente por um dos setores do ordenamento jurídico - como uma blindagem aos excessos sancionadores e à expansão simbólica das respostas penais. Evitase, de conseguinte, a aplicação de uma sanção além da reprovabilidade/censura da conduta, uma multiplicidade de processos desnecessários e se consolida a vedação de sobreposição concomitante de sanção administrativa e penal sobre a mesma pessoa com base no mesmo fato e iguais fundamentos. Considera-se, em síntese, a imposição de uma resposta sancionadora unívoca do ordenamento jurídico, o que contribui para uma orientação político-criminal minimalista. 


\section{RESPONSABILIDADE DAS PESSOAS JURÍDICAS EM INFRAÇÕES AMBIENTAIS EM FACE DO PRINCÍPIO DO NE BIS IN IDEM: UMA ABORDAGEM POLÍTICO-CRIMINAL}

Insta relembrar que resguardar a densidade normativa do princípio do ne bis in idem em si não implica prejulgar a solução normativa concreta ${ }^{42}$, já que a ideia de subordinação do poder administrativo sancionador ao Direito Penal é externa ao conteúdo do referido princípio.

Desta forma, considerando o exemplo ora em análise, se a intervenção administrativa ocorrer previamente à intervenção penal, além de ser mais adequada no que diz respeito à responsabilização da pessoa jurídica ${ }^{43}$, impedirá - através do princípio do ne bis in idem - a intervenção penal sobre o mesmo fato em face da mesma pessoa jurídica, salvo se baseada em fundamentos distintos.

Todavia, é preciso destacar que, quando aplicada uma sanção administrativa a um mesmo fato tido simultaneamente como um ilícito ambiental administrativo e também como um ilícito ambiental penal a uma pessoa jurídica, seu posterior desconto na sanção penal imposta estaria em conformidade com o ne bis in idem, segundo a jurisprudência espanhola, pois teriam sido observados os princípios da culpabilidade e da proporcionalidade. ${ }^{44}$

Outrossim, é imprescindível ressaltar que o direito administrativo sancionador também pode, em determinadas situações, sancionar condutas graves - e não apenas leves - que lesionem um bem jurídico. Aliás, é possível vislumbrar dois campos de atuação do direito administrativo sancionador: proteção de bens jurídicos e garantia de observância às normas organizacionais fundamentais para o regular funcionamento da Administração. E é no primeiro âmbito que pode ser admissível uma dupla atuação do poder sancionador administrativo e do

\footnotetext{
${ }^{42}$ GARCÍA ALBERO, Ramón. Non bis in idem: material y concurso de leyes penales. Barcelona: CEDECS, 1995. p. 85.

43 "Em matéria de infrações administrativas, não existe um especial problema em aceitar como sujeitos da sanção as pessoas jurídicas". Cf. En materia de infracciones administrativas, no existe un especial problema en aceptar como sujetos de la sanción a personas jurídicas. CORCOY BIDASOLO, Mirentxu; GALLEGO SOLER, José Ignacio. Infracción administrativa e infracción penal en el ámbito del delito medioambiental: ne bis in idem material y procesal: comentario a la STC 177/199, de 11 de octubre. Actualidad Penal, Madrid, v. 1, n. 8, p. 159178., fev. 2000. p. 163.

${ }^{44}$ Cf. o teor contido na STS 833/2002, de 02 de julho, proferida pelo Tribunal Constitucional da Espanha na qual se decidiu que o desconto na sentença penal do conteúdo da sanção administrativa estaria em consonância com os valores da Constituição. Segundo a referida decisão: "Não se produz reiteração punitiva, proibida constitucionalmente, embora haja identidade de sujeito, fato e fundamento, quando o órgão judicial toma em consideração a anterior sanção administrativa para seu desconto na pena em fase de execução da sentença penal. Materialmente somente existiu uma sanção. $\mathrm{O}$ art. 25.1, CE não proíbe a 'dupla reprovabilidade aflitiva', mas a reiteração sancionadora não basta (...) para considerar vulnerado o direito fundamental na sua vertente material a mera declaração da imposição da sentença". (Cf. CUERDA RIEZU, Antonio. El descuento o la compensación como criterio para evitar un bis in idem. Cumplimiento de la Constitución con incumplimiento de la ley?. In: MUÑOZ CONDE, Francisco et al. Un derecho penal comprometido: libro homenaje al Prof. Gerardo Landrove Díaz. Valencia: Tirant lo Blanch, 2011. p. 240). Antonio Cuerda Riezu entende que tal técnica de desconto deveria ter previsão legal para satisfazer as necessidades do ne bis in idem. (Cf. CUERDA RIEZU, Antonio. El descuento o la compensación como criterio para evitar un bis in idem. Cumplimiento de la Constitución con incumplimiento de la ley?. In: MUÑOZ CONDE, Francisco et al. Un derecho penal comprometido: libro homenaje al Prof. Gerardo Landrove Díaz. Valencia: Tirant lo Blanch, 2011. p. 266).
} 
Direito Penal em níveis distintos de tutela, diferença esta mensurada quanto ao fundamento das respectivas normas. Todavia, não é possível admitir a intervenção do Direito Penal para sancionar meras desobediências a normas meramente administrativas.

Segundo se assinala, o poder sancionador do Estado não é único ${ }^{45}$, o que permite considerar que o poder punitivo do Estado e o poder sancionador administrativo atuam em esferas distintas, porém inter-relacionadas, e que podem atuar por meio de uma política sancionatória integrada. Assim, Helena Regina Lobo da Costa afirma que "o reconhecimento do ne bis in idem quanto às esferas penal e administrativa não deve ser efetuado de modo isolado. Consoante já afirmado, ele deve ser inserido em uma política criminal com olhar amplo, que considere também outras formas de sancionamento de condutas - e que pode ser denominada de política sancionadora." 46

Considerar a ausência de identidade entre o poder sancionador administrativo e o poder punitivo do Estado significa reconhecer a impossibilidade de transladar automaticamente os princípios e garantias processuais penais tais como eles se apresentam ao processo administrativo em que o poder sancionador impõe uma sanção de caráter administrativo, uma vez que se deve considerar as especificidades inerentes a cada um dos ramos do Direito. ${ }^{47}$

Todavia, isto não quer dizer que quando da atuação do poder sancionador administrativo para imposição de uma sanção de caráter administrativa não tenha que se assegurar um conjunto mínimo de garantias em prol daquele que está sujeito ao referido poder sancionador administrativo; porém, isso se deve em virtude da necessidade de se esboçar princípios gerais do Poder Sancionador do Estado e não em decorrência de suposta identidade com o Direito Penal, mas sim com fundamento constitucional ${ }^{48}$

Isto porque "nessa lógica, a atividade sancionatória do Estado, quer quando da aplicação de sanções pela própria administração (sanções administrativas), quer em razão da aplicação de sanção pelo Poder Judiciário (sanção penal), deve atender a um conjunto de regras

\footnotetext{
${ }^{45}$ COSTA, Helena Regina Lobo da. Direito Penal Econômico e Direito Administrativo Sancionador: ne bis in idem como medida de política sancionadora integrada. Tese de Livre Docência. Faculdade de Direito da Universidade de São Paulo. São Paulo. 2013. p. 176.

${ }^{46}$ Ibid., p. 227.

${ }^{47}$ Ibid., p. 176. Segundo Luiz Flávio Borges D’Urso, “isto não significa que os princípios do regime jurídico punitivo tenham aplicabilidade igual e direta em todas as situações, mas que se deve sempre observar um núcleo de garantias, sem deixar de respeitar as peculiaridades de cada um dos ramos do Direito Penal e do Direito Administrativo Sancionador". (D’URSO, Luiz Flávio Borges. Menos Direito Penal e Mais Direito Administrativo Sancionador. In: BLAZECK, Luiz Mauricio Souza; MARZAGÃO JR., Laerte I.; ALCKMIN, Geraldo. Direito administrativo sancionador. São Paulo: Quartier Latin, 2014. p. 207).

${ }^{48}$ Ibid., p. 177.
} 


\section{RESPONSABILIDADE DAS PESSOAS JURÍDICAS EM INFRAÇÕES AMBIENTAIS EM FACE DO PRINCÍPIO DO NE BIS IN IDEM: UMA ABORDAGEM POLÍTICO-CRIMINAL}

de contenção do poder de punir, independentemente da espécie da sanção"; ${ }^{49}$ bem como "é sob essa ótica, e a partir desse regramento constitucional, que o poder punitivo do Estado, algo único, deve ser interpretado, independentemente de se tratar do Estado Administração ou do Estado Juiz". 50

Por fim, verifica-se que o grande desafio consiste em delimitar quais seriam estes princípios gerais do Poder Sancionador do Estado que devem incidir necessariamente nos processos administrativos em que se impõe uma sanção de natureza administrativa, especialmente quando esta implicar em uma restrição significativa aos direitos fundamentais da pessoa, seja ela física ou jurídica.

O princípio do ne bis in idem pode, assim, funcionar como estratégia de contenção de iniciativas criminalizadoras, pois reforçar o caráter simbólico da intervenção penal e fundamentar sua extensão às pessoas jurídicas, ainda que a sanção penal aplicada seja idêntica àquela prevista no ordenamento administrativo sancionador, apenas contribui para a articulação de uma política criminal orientada à expansão do poder punitivo, em detrimento de princípios garantistas elementares.

\section{REFERENCIAS}

AGOSTINI, Alexandra Comar de; JUNIOR, Arnaldo Hossepian S. L. A invasão incondicional da lei penal e o direito administrativo sancionador como mecanismo de Legitimação e Controle do Poder Punitivo do Estado. In: BLAZECK, Luiz Mauricio Souza; MARZAGÃ̃O JR., Laerte I.; ALCKMIN, Geraldo. Direito administrativo sancionador. São Paulo: Quartier Latin, 2014. p. 15-31.

BARJA DE QUIROGA, Jacobo López. El principio: non bis in idem. Madrid: Dykinson, 2004.

BUSATO, Paulo César, GUARAGNI, Fábio André. Responsabilidade penal da pessoa jurídica. Curitiba: Juruá, 2012.

CARVALHO, Érika Mendes de; CARDOSO, Sônia Letícia de Méllo; SANTIAGO, Nestor Eduardo Araruna. Duplicidade de sanções ambientais e o princípio non bis in idem. In: Pensar:

${ }^{49}$ AGOSTINI, Alexandra Comar de; JUNIOR, Arnaldo Hossepian S. L. A invasão incondicional da lei penal e o direito administrativo sancionador como mecanismo de Legitimação e Controle do Poder Punitivo do Estado. In: BLAZECK, Luiz Mauricio Souza; MARZAGÃO JR., Laerte I.; ALCKMIN, Geraldo. Direito administrativo sancionador. São Paulo: Quartier Latin, 2014. p. 290.

${ }^{50}$ AGOSTINI, Alexandra Comar de; JUNIOR, Arnaldo Hossepian S. L. A invasão incondicional da lei penal e o direito administrativo sancionador como mecanismo de Legitimação e Controle do Poder Punitivo do Estado. In: BLAZECK, Luiz Mauricio Souza; MARZAGÃO JR., Laerte I.; ALCKMIN, Geraldo. Direito administrativo sancionador. São Paulo: Quartier Latin, 2014. p. 290.

Rev. de Criminologias e Políticas Criminais | e-ISSN: 2526-0065 | Maranhão | v. 3 | n. 2 | p. 49 - 67 | Jul/Dez. 2017 
Revista de Ciências Jurídicas, vol. 18, n. 2, p. 431 - 469. Fortaleza: Universidade de Fortaleza, mai/ago 2013.

CARO CORIA, Dino Carlos. El principio de "ne bis in idem" en la jurisprudencia del Tribunal Constitucional. Revista Brasileira de Ciências Criminais, São Paulo, v. 15, n. 66, p. 9-52., mai./jun. 2007.

COSTA, Helena Regina Lobo da. Direito Penal Econômico e Direito Administrativo Sancionador: ne bis in idem como medida de política sancionadora integrada. Tese de Livre Docência. Faculdade de Direito da Universidade de São Paulo. São Paulo. 2013.

COSTA, Helena Regina Lobo da. Proteção Penal Ambiental: viabilidade, efetividade e tutela por outros ramos do Direito. São Paulo: Saraiva, 2010.

CORCOY BIDASOLO, Mirentxu; GALLEGO SOLER, José Ignacio. Infracción administrativa e infracción penal en el ámbito del delito medioambiental: ne bis in idem material y procesal: comentario a la STC 177/199, de 11 de octubre. Actualidad Penal, Madrid, v. 1, n. 8, p. 159-178., fev. 2000.

CUERDA RIEZU, Antonio. El descuento o la compensación como criterio para evitar un bis in idem. Cumplimiento de la Constitución con incumplimiento de la ley?. In: MUÑOZ CONDE, Francisco et al. Un derecho penal comprometido: libro homenaje al Prof. Gerardo Landrove Díaz. Valencia: Tirant lo Blanch, 2011. p. 239-266.

D’URSO, Luiz Flávio Borges. Menos Direito Penal e Mais Direito Administrativo Sancionador. In: BLAZECK, Luiz Mauricio Souza; MARZAGÃO JR., Laerte I.; ALCKMIN, Geraldo. Direito administrativo sancionador. São Paulo: Quartier Latin, 2014. p. 203-210.

OLIVARES, Gonzalo; MORALES PRATS, Fermín (Coord.). El nuevo derecho penal español: estudios penales en memoria del profesor José Manuel Valle Muñiz. Pamplona: Aranzadi, 2001. p. 295-400.

OTTAVIANO, Santiago. Sanción penal, sanción administrativa y ne bis in idem. In: YACOBUCCI, Guillermo Jorge; LAPORTA, Mario H.; RAMÍREZ, Nicolás D. Derecho penal empresario. Montevidéu: B. de F., 2010. p. 739-797.

GARCÍA ALBERO, Ramón. La relación entre ilícito penal e ilícito administrativo: texto y contexto de las teorías sobre la distinción de ilícitos. In: QUINTERO OLIVARES, Gonzalo; MORALES PRATS, Fermín (Coord.). El nuevo derecho penal español: estudios penales en memoria del profesor José Manuel Valle Muñiz. Pamplona: Aranzadi, 2001. p. 295-400.

GARCÍA ALBERO, Ramón. Non bis in idem: material y concurso de leyes penales. 1. ed. Barcelona: CEDECS, 1995.

GARCÍAS PLANAS, Gabriel. Consecuencias del principio non bin in idem en derecho penal. Anuario de derecho penal y ciencias penales, Madrid, v. 42, n. 1, p. 109-123., jan./abr. 1989. 
HASSEMER, Winfried. Derecho penal simbólico y protección de bienes jurídicos. Trad. Elena Larrauri. Nuevo Foro Penal 51/22, 1991.

HENDLER, Edmundo S. Una regla que confirma sus excepciones: ne bis in idem. In: HENDLER, Edmundo S. Las garantías penales y procesales: enfoque histórico-comparado. Buenos Aires: Del Puerto, 2004. p. 131-148.

MAÑALICH R., Juan Pablo. El principio ne bis in idem en el derecho penal chileno. Revista peruana de ciencias penales, Lima, n. 26, p. 351-386., 2013.

PASTOR, Daniel R. Nuevas tareas para el principio ne bis in idem?. In: ANITUA, Gabriel Ignacio; TEDESCO, Ignacio F. La cultura penal: homenaje al professor Edmundo S. Hendler. Buenos Aires: Del Puerto, 2009. p. 497-513.

PIOVESAN, Flavia. O valor jurídico dos tratados e seu impacto na ordem internacional. In: PIOVESAN, Flavia. Temas de direitos humanos. 9. ed. São Paulo: Saraiva, 2016. p. 163-175.

PRADO, Luiz Regis. Responsabilidade penal da pessoa jurídica (uma perspectiva do direito brasileiro). In: DOTTI, René Ariel; PRADO, Luiz Regis (Coords.). Responsabilidade penal da pessoa jurídica: em defesa do princípio da imputação subjetiva. 4.ed. São Paulo: RT, 2013.p. 129-162.

PUERTA, Luis-Román. Duplicidad sancionadora, administrativa y penal, non bis in idem. In: MARTÍN PALLÍN, José Antonio (Dir.). Extranjeros y derecho penal. Madrid: Consejo General del Poder Judicial, 2004. p. 35-63.

SABOYA, Keity. Ne bis in Idem: História, Teoria e Perspectivas. Rio de Janeiro: Lumen Juris, 2014.

SHECAIRA, Sérgio Salomão. Responsabilidade penal da pessoa jurídica. 2. ed. São Paulo: Método, 2003.

SILVEIRA, Renato de Mello Jorge; GOMES JUNIOR, João Florêncio de Salles. Direito penal, direito administrativo sancionador e a questão do ne bis in idem: o parâmetro da jurisprudência internacional. In: BLAZECK, Luiz Mauricio Souza; MARZAGÃO JR., Laerte I.; ALCKMIN, Geraldo. Direito administrativo sancionador. São Paulo: Quartier Latin, 2014. p. 287-306.

SILVEIRA, Renato de Mello Jorge. Direito penal supra-individual: interesses difusos. São Paulo: Revista dos Tribunais, 2003.

VICENTE MARTÍNEZ, Rosario de. Teoría y práctica o el dr. Jekyll y Mr. Hyde: a propósito de la sentencia del Tribunal Constitucional 177/1999, de 11 de octubre, sobre el principio ne bis in idem. Actualidad Penal, Madrid, v. 2, n. 22, p. 473-486., jun. 2000. 